\begin{tabular}{|c|c|c|}
\hline $\begin{array}{l}\text { PKS } \\
\text { PUBLIC } \\
\text { KNOLLEDGE } \\
\text { PROJECT }\end{array}$ & $\begin{array}{c}\text { Revista de GEOGRAFIA } \\
\text { (RECIFE) } \\
\text { http://www.revista.ufpe.br/revistageografia }\end{array}$ & 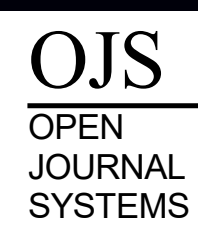 \\
\hline
\end{tabular}

\title{
TERRITORIALIDADES URBANAS E PRODUÇÃO DE CONHECIMENTOS CONTEXTUALIZADOS COM O SEMIÁRIDO BRASILEIRO: A EXPERIÊNCIA DO PROGRAMA REDE AMBIENTAL PARA CONSTRUÇÃO DO SISTEMA DO VERDE URBANO E MOBILIDADE SUSTENTÁVEL NA CIDADE DE JUAZEIRO (BA)
}

\author{
Luzineide Dourado Carvalho ${ }^{1}$ \\ ${ }^{I}$ Docente da Universidade do Estado da Bahial Departamento de Ciências Humanas. Email: \\ ldcarvalho@uneb.br
}

Artigo recebido em 11/09/2017 e aceito em 01/10/2017

\begin{abstract}
RESUMO
$\mathrm{O}$ artigo discute as territorialidades urbanas do Semiárido contemporâneo. Com base no percurso teóricometodológico do projeto de pesquisa CONVIVERDE, tais processos sócio territoriais são analisados pela complexidade e decolonialidade afim de revelar os desafios das relações sociedade e natureza para a construção de sistemas urbanos pautados na lógica sustentável. O projeto de pesquisa CONVIVERDE, atua de forma interdisciplinar e contextualizada no sentido de criar e consolidar a Rede Ambiental do verde urbano e mobilidade sustentável nas cidades semiaridas.

Palavras-chaves: Verde urbano. Convivência com Semiarido. Rede Ambiental.

\section{URBAN TERRITORIALITIES AND KNOWLEDGE PRODUCTION CONTEXTUALIZED WITH THE BRAZILIAN SEMIÁRIDO: THE EXPERIENCE OF THE ENVIRONMENTAL NETWORK PROGRAM FOR THE CONSTRUCTION OF THE URBAN GREEN SYSTEM AND SUSTAINABLE MOBILITY IN THE CITY OF JUAZEIRO (BA)}

\begin{abstract}
The article discusses the urban territorialities of contemporary Semiarid. Based on the theoreticalmethodological path of the CONVIVERDE research project, such socio-territorial processes are analyzed by complexity and decoloniality in order to reveal the challenges of society and nature relations for the construction of urban systems based on sustainable logic. The CONVIVERDE research project works in an interdisciplinary and contextualized way in order to create and consolidate the Green Urban Environmental Network and sustainable mobility in semiarid cities.

Keywords: Urban green. Living with semiárido. Environmental network.
\end{abstract}




\section{CONSIDERAÇÕES INICIAIS}

Neste artigo, apresenta-se o relato de experiência do Projeto de Pesquisa Programa de Redes Ambientais para Construção do Sistema do Verde Urbano e Mobilidade Sustentável na Cidade de Juazeiro (BA): Um Processo Participativo de Ações Contextualizadas para Convivência com o Semiárido Baiano" ou CONVIVERDE. O referido projeto é desenvolvido pelo Núcleo de Estudos e Pesquisa em Educação Contextualizada para a Convivência com o Semiárido Brasileiro (NEPEC-SAB), da Universidade do Estado da Bahia/Departamento de Ciências Humanas, Campus III (UNEB/DCHIII), em parceria com o Laboratório de Conforto Ambiental da Escola de Arquitetura da Universidade Federal da Bahia (LACAM/EAU/UFBA) e foi apoiado pela Fundação de Amparo à Pesquisa do Estado da Bahia (FAPESB) ${ }^{1}$.

O Projeto nasce do intuito de se problematizar o crescimento urbano do território Semiárido Brasileiro ${ }^{2}$, investigando as condições ambientais de uso e disponibilidade dos espaços verdes (de lazer e recreação, dentre outros), e dos significados simbólico-culturais que os habitantes constroem sobre o viver e o conviver com o Semiárido, no meio urbano.

O projeto tem como objetivo principal analisar o sistema de relações existentes entre o meio ambiente Semiárido e as cidades médias, buscando investigar como o crescimento urbano acelerado de tais cidades tem disposto o uso e a apropriação dos espaços urbanos, impactando a qualidade do ambiente e da vida dos seus habitantes, bem como, apreender como os sujeitos citadinos, estabelecem ou não, a valorização, preservação e conservação do patrimônio natural, social e simbólico-cultural desses espaços. A partir desse pressuposto, a pesquisa toma como estudo de caso, a cidade de Juazeiro (BA).

Dentre os objetivos específicos, o Programa de Rede Ambiental do Verde Urbano deseja despertar o interesse da população para a questão da qualidade ambiental do espaço urbano de sua cidade por meio de workshops e seminários; gerar conhecimentos contextualizados com o Semiárido Brasileiro e Baiano; criar um Parâmetro de qualidade ambiental referenciado ao verde urbano e a mobilidade sustentável, que seja replicável

\footnotetext{
${ }^{1}$ Edital 008/2012 para Apoio a Projetos de Pesquisa e a Articulação em Rede para o Semiárido Baiano, Projeto $\mathrm{n}^{\mathrm{o}} 4967$.

${ }^{2}$ Semiárido Brasileiro é a cartografia compreendida pelo Programa Nacional de Combate à Desertificação (PAN-Brasil), lançado em 2005 pela Secretaria de Recursos Hídricos do Ministério do Meio Ambiente (BRASIL, 2004). De acordo com esse Programa (baseado na Convenção Mundial de Combate à Desertificação), se inserem como Semiárido as áreas semiáridas, sub-úmidas secas e do entorno dos estados do Nordeste, norte de Minas Gerais e noroeste do Espírito Santo. 
também em cidades pequenas e médias do Semiárido Brasileiro, além de promover ações educativas contextualizadas em escolas públicas da rede municipal de ensino para a sensibilização e inserção da Educação Contextualizada para a Convivência com o Semiárido Brasileiro (ECSAB).

Toma-se como estudo de caso, o centro e a periferia do município de Juazeiro (BA), desenvolvendo análises documentais e do acervo fotográfico da evolução urbana da cidade; coleta de dados empíricos por meio de medições microclimáticas, diagnóstico da arborização de ruas e espaços públicos de lazer dentre outras pesquisas. Além de um trabalho pedagógico de Educação Contextualizada (ECSAB), em cinco escolas públicas municipais a partir de oficinas de desenhos/mapas mentais com alunos e formação continuada, ofertando cursos de extensão, encontros e assessoria pedagógica com os docentes e gestores dessas escolasparceiras $^{3}$

O Projeto segue um viés interdisciplinar e complexo para pensar as questões do Semiárido urbano contemporâneo, atuando com três grandes áreas do conhecimento, que são: Geografia, Arquitetura e Educação. E, desenvolve cinco subprojetos, a saber: Áreas verdes urbanas; Mobilidade sustentável; Microclima Urbano; Memória e Cidade; Conviverde nas Escolas.

Tem como grande meta criar a Rede Ambiental de Juazeiro como forma participativa, institucional de gestar as questões socioambientais dessa cidade, tanto já realizou quatro (04) Encontros de Parceiros, que foram momentos que objetivaram apresentar resultados parciais do projeto quanto identificar e fortalecer os parceiros para a constituição da Rede Ambiental, ocorrida no último encontro, dia 08 de junho de 2016.

Apresenta-se nesse relato de experiência, os resultados obtidos nessa primeira fase e algumas considerações sobre as territorialidades sertanejas a partir da convivência com essa cidade semiárida.

\section{AS DINÂMICAS URBANAS DO SEMIÁRIDO BRASILEIRO CONTEMPORÂNEO}

O sistema-mundo moderno baseado na Ciência dura distanciou o homem da natureza, afirma Morin (2005). No entanto, o século XXI, a humanidade cada vez mais questiona tais paradigmas e busca mudanças na percepção e na concepção de um novo/outro

\footnotetext{
${ }^{3}$ Escolas Municipais: Carmem Costa, Leopoldina Leal, Ludgero, Haydée Fonseca; Pró Menor. Carvalho, $2018 \quad$ ISSN 0104-5490 3
} 
sistema-mundo, mais dialógico, mais contextual e mais relacional com os ecossistemas socioambientais.

O Semiárido Brasileiro (SAB) é um ecossistema ambiental susceptível às secas, à degradação das terras e ao processo de desertificação, sendo, portanto, definido pela Convenção Mundial de Combate à Desertificação (UNCCD ou CCD) como parte das "Áreas Susceptíveis à Desertificação" (ASD) do mundo, as chamadas "terras secas'(MMA/SRH, 2004, p.16).

Deste modo, ao se tratar das questões urbanas do Semiárido, temos que dimensionar este território dentro de uma totalidade, e não em partes, como faz o paradigma positivistacartesiano, mas vendo-o de forma complexa e relacional, no qual o urbano e o rural são partes que se dialogam e se comunicam em diferentes dimensões, sejam econômicas, produtivas, socioculturais e ambientais.

O SAB tem sido concebido como lugar de repulsa, de estranhamento, de hostilidade, cuja presença da Caatinga e das secas, marcam a literatura, os discursos, as imagens cinematográficas, músicas etc. Um ambiente posto como hostil e habitado por sobreviventes, precariamente, os catingueiros, apáticos e engessados às agruras da natureza (CARVALHO, 2012).

Esse território também tem sido mais compreendido pela característica rural, e esta interpretação nega a dinâmica urbana que tem se configurado nas últimas décadas:

Analisando o comportamento da população das ASD entre os anos de 1991 e 2000 verifica-se que, em regra geral, este extrato populacional diminuiu consideravelmente. Apenas nos Estados de Alagoas e Sergipe, e em alguns poucos municípios das ASD, registram-se taxas de crescimento populacional positivas. Em $72,6 \%$ dos municípios houve redução da população na zona rural. Em todas as ASD, mais de um milhão de pessoas deixou o campo no período de 1991/2000 (BRASIL, 2007, p,57)

Estes dados do Atlas das Áreas Susceptíveis à Desertificação (ASD), afirmam que, a tendência do Brasil das últimas décadas há uma redução da população rural, que no Semiárido, este comportamento, por sua vez, deve ser analisado considerando que a maior parte dos seus munícipios guardam características de cidades rurais, como define Abramovay (2003) para cidades de até 50 mil habitantes. Isto porque tais municípios têm a maior parte da população vivendo na zona rural. Deste modo, a redução da população rural do Semiárido 
deve-se ao crescimento e à concentração urbana da população de algumas cidades, como exemplo, Juazeiro (BA) e Petrolina (PE):

Analisando a tendência populacional urbana nas ASD entre os anos de 1991 e 2000 verificou-se que a taxa de crescimento deste extrato foi positiva na maioria dos municípios estudados na área total, o crescimento médio anual foi de 2,5\%. A concentração nas cidades também aumentou neste período. Em 1991, a taxa de urbanização foi de 54,7\% enquanto que em 2000 subiu para $62,4 \%$. Apesar desse aumento, a região ainda é uma das menos urbanizadas do país. A taxa de urbanização nacional em 2000 era de 82\% (BRASIL, 2007, p.58).

O SAB é considerado dentro das 'terras secas', o mais populoso do mundo (BRASIL, 2007). E, deste modo, faz-se necessário avançar em políticas publicas sociais que atendam a crescente demanda de sua população rural e urbana. Se este território cada vez mais se torna urbano, por sua vez, o crescimento desordenado cria iniquidades e problemas ambientais urbanos, que crescem em proporções elevadas: A ausência de coleta seletiva, a rede hidrográfica poluída, arborização ausente ou descontextualizada, ausência ou insuficiente saneamento e tantos outros problemas. Associado a este (des) contexto, o habitante da cidade do Semiárido desconhece as peculiaridades do seu território, e se desconhece como sujeito do mesmo, revelando a fragilidade na construção de sua territorialidade como expressão de pertencimento. Como nos diz Bonnemaison (2002), os homens podem ligar-se ou excluir-se de seu território por meio da maior ou menos intensidade de sua territorialidade.

Deste modo, viver e conviver no urbano do Semiárido é também uma questão que transversaliza os processos educativos, pois uma educação que não tematiza as questões de seu território favorece a manutenção dos estigmas e negatividades do SAB como território da seca, da fome e da pobreza, como afirma Carvalho (2012).

Tais questões são muito graves ao situarmos a posição relevante de Juazeiro dentro do contexto economcio do SAB. Em conjunto com Petrolina (PE), estes municípios formam o importante polo de agroindústria do Vale do São Francisco, e por sua vez, um centro estratégico de desenvolvimento territorial do SAB.

Apesar desse avanço regional, os desafios a serem enfrentados por esses municípios são de cunho econômico, coordenação institucional e estabelecimento de parcerias, sociocultural e político e essencialmente educacional para avançar num modelo de desenvolvimento territorial mais justo socialmente e prudente ambientalmente. Nesse aspecto, 
necessário se faz avançar no paradigma da Convivência com o Semiárido Brasileiro como contraponto ao modelo agroexportador, desigual e degradador que predomina no Vale do São Francisco.

\section{O ITINERÁRIO TEÓRICO-METODOLÓGICO}

Segundo Carvalho (2010) são por meio dos fenômenos que pode-se ir até as bases fundadoras das significações de hostilidade, das falas instituídas sobre a natureza, o território e as gentes sertanejas, pois são conotadas de estereotipia, dominação e externalidade. Deste modo, o CONVIVERDE elenca a fenomenologia como método de pesquisa, na perspectiva de observar qual a relação dos sujeitos com sua cidade, e assim, compreender como esses percebem sua existência no mundo, que é também do sertão Semiárido.

Esse itinerário teórico-metodológico numa abordagem fenomenológica se constitui um diálogo de saberes que se faz pelas três áreas de conhecimento: A Geografia, Arquitetura e a Educação, portanto, um viés interdisciplinar, contextualizado e complexo.

No que tange à Geografia, apoia-se nas abordagens da Geografia Cultural-Humanista para apreender os sentidos das territorialidades sertanejas e do espaço vivido num contexto urbano. Nesse sentido, apoia-se em Tuan (1983), considerando que este desenvolveu uma análise sobre espaço e lugar, na perspectiva da experiência que as pessoas vivenciam em determinado local. Para esse teórico, o que começa como espaço indiferente transforma-se em lugar à medida que o conhecemos melhor e o dotamos de valor, em suma, que o experienciamos.

A perspectiva cultural de Holzer (2003) colabora na compreensão da valorização do indivíduo à espacialidade, e as formas como evidencia suas geograficidades. Como diz (p.12): "uma descrição rigorosa do mundo vivido da experiência humana e, com isso, através da intencionalidade, reconhecer as "essências" da estrutura perceptiva".

A partir da Arquitetura Sustentável, o Projeto considera os pressupostos do Conforto Ambiental e do Verde Urbano para se pensar a 'cidade sustentável' ou 'cidade inteligente', que de acordo com Roseland (2017), é o tipo mais durável de assentamento que o humano é capaz de construir, uma vez que é capaz de propiciar um padrão de vida aceitável sem causar profundos prejuízos ao agroecossistema ou aos ciclos biogeoquímicos de que ela depende. Portanto, estes fundamentos contribuem para pensar as cidades semiáridas como cidades sustentáveis, mas certamente, necessita-se da criação de uma nova lógica de funcionamento, 
gestão e crescimento dessas cidades, em especial, apropriadas às condições climáticas, aspecto que ainda é muito desconsiderado na Arquitetura convencional.

E, no que tange à Educação, o CONVIVERDE, elege-se à Educação Contextualizada, elencando-a como percurso para a construção do pensamento complexo e decolonial pelos sujeitos do processo educativo. Deste modo, ao buscarmos compreender o que é espaço urbano da cidade de Juazeiro nas falas, desenhos e memória dos sujeitos da pesquisa, que são transeuntes abordados nas enquetes e questionários sobre a mobilidade urbana, memória do verde da cidade etc., com crianças e professores das escolas-parceiras e outros, significa que elegemos um objeto fenomenologicamente determinado no espaço geográfico - a cidade, e que, portanto, nossa intenção foi apreender a geografia vivida destes sujeitos, como diz Holzer (2003), a geografia vivida nos permite explorar o mundo e as ligações de cada homem com a terra nativa.

A partir dessa base teórico-metodológica, a pesquisa se compromete com a construção de outro/novo paradigma ambiental, que requer da Universidade pensar a cidade e suas inter-relações territoriais e suas diferentes redes, para ser um lugar de vida e para a vida, aqui no caso, do território Semiárido Brasileiro.

A seguir, será apresentada uma síntese de cada subprojeto do CONVIVERDE, expondo seus objetivos e ações realizadas:

\section{- Áreas Verdes Urbanas:}

As contribuições das áreas verdes e seus múltiplos papéis para a qualidade de vida, no ambiente urbano são inquestionáveis. Carvalho (1999) verificou que existe um forte elo afetivo entre as pessoas e o ambiente natural, embora na cidade, exista um grande desconhecimento da importância não somente das funções ecológicas, como econômicas, bem como papel social das áreas verdes urbanas, o que leva a uma distorção na valorização destes espaços e à sua destruição.

Justamente esse Subprojeto tem o intuito de situar a importância das áreas verdes em espaços públicos da cidade de Juazeiro, cujas condições semiáridas são bem acentuadas, com temperatura média anual acima de $25^{\circ} \mathrm{C}$ e alta evapotranspiração, e uma vez as praças, jardins, parques e ruas arborizadas comportam-se como amenizadores da alta insolação e baixa umidade do ar.

Ressalta Carvalho (1999) que as áreas verdes podem ser utilizadas para manter as condições atmosféricas das cidades favoráveis ao conforto térmico, à saúde e ao bem estar da população além de exercer importante e essencial função do verde, no que tange à qualidade 
do meio ambiente urbano. Tal aspecto é fundamental em qualquer bioma e, se tratando da Caatinga, torna-se relevante problematizar quanto à ausência do verde contribuiu para o aumento da semiaridez.

O subprojeto tem problematizado além da importância da arborização para uma cidade semiárida, a adequação das espécies na arborização dos espaços públicos de Juazeiro, buscando identificar as características vegetativas regionais, predominadas pela Caatinga, e como essas se apresentam no espaço urbano dessa cidade.

Os espaços verdes nos contextos semiáridos são substanciais para conservação de sua flora, fauna, clima, potencial pluviométrico, conforto térmico etc., mas o que foi diagnosticado em Juazeiro são seus espaços urbanos arborizados de forma dissociada do Bioma Caatinga, com plantas exóticas, além de predominar as duas espécies, Ficus benjamina e $\mathrm{Nim}^{4}$, que tornam a paisagem urbana homogênea.

O Subprojeto criou um banco fotográfico, com imagens da arborização presente na cidade e foram registrados espaços com pouco verde, sem muito uso estético, de lazer e social, e alguns espaços como ruas e canteiros com árvores exóticas. Esse diagnóstico demonstra à necessidade de se propagar a vegetação nativa da Caatinga nas áreas como praças, parques, ruas, evidenciando os benefícios que isto traz para a valorização da flora regional, de rica diversidade, cujas espécies são de grande potencial florístico além de outros. E, assim apontar a Caatinga como uma vegetação nativa que também atende aos requisitos e funções para a arborização urbana das cidades do SAB.

- Mobilidade Sustentável

O termo mobilidade sustentável indica a maneira de se mover de um lugar para outro e, em geral, indica um sistema de mobilidade urbana que pode diminuir os impactos sociais e econômicos gerados por veículos particulares, ou seja, a poluição do ar e as emissões de gases de efeito estufa, a poluição sonora, o congestionamento rodoviário, o índice de acidentes, a deterioração das áreas urbanas (causada pelo espaço ocupado pelos veículos à custa de pedestres), o consumo de espaço (causado pela concretização de estradas e infraestruturas) (SCHAFER, 1998).

Encorajar a "mobilidade alternativa" é de vital importância para as cidades modernas, uma vez que, o uso de andar a pé, de bicicleta, ampliação de transportes públicos em sistema integrado de ônibus, trem elétrico e metrôs, cria uma infraestrutura de mobilidade sustentável e gera um contributo positivo para as comunidades urbanas.

${ }^{4}$ Azadirachta. 
Nessa perspectiva, o subprojeto de Mobilidade Sustentável objetivou diagnosticar sobre a situação do trânsito e das condições necessárias para se locomover na cidade de Juazeiro, considerando a importância de uma educação para o trânsito como condição para uma boa circulação de pessoas e veículos.

Hoje se percebe que as cidades, de modo geral, e sobretudo Juazeiro-BA (em conjunto com Petrolina-PE, que formam juntas um grande polo urbano regional) vêm crescendo muito nos últimos anos e, com o aumento da população, também aumentou-se o número de veículos individuais motorizados. No entanto, a estrutura urbana não se mostra adequada a facilitar o deslocamento de milhares de carros, motos, caminhões e ônibus todos os dias, consequência de uma estrutura não planejada no passado, e que atualmente se reflete em ruas e avenidas com poucos espaços para circularem veículos, muito menos, consorciá-los com pedestres.

A metodologia se baseou na aplicação de uma enquete junto a cem (100) usuários de diferentes meios de transporte, em pontos selecionados do centro urbano. Os resultados mostraram uma situação caótica devido ao aumento dos veículos motorizados e da ausência de modelo eficiente e eficaz de mobilidade.

Após sistematizar os dados da enquete, foram identificadas algumas sugestões para a superação dos problemas da mobilidade, a saber: A população deseja melhorias na infraestrutura viária da cidade, por exemplo, a construção de ruas e avenidas maiores do que as atuais na sua largura; a melhoria das calçadas deterioradas; o maior número de estacionamentos; a construção de um anel viário etc. Em relação ao desenvolvimento de projetos sustentáveis, muitos citaram a criação de ciclovias, criação de corredores exclusivos para ônibus, maior planejamento urbano, maior arborização e padronização das calçadas, criação de campanhas educativas e profissionais para a boa condução do trânsito etc.

Conclui-se que os cidadãos mostram-se conscientes do que significa ter uma mobilidade mais sustentável e adequada para as cidades do semiárido, no entanto, muitos desacreditam da implantação de um modelo de tal envergadura.

\section{-Microclima Urbano:}

O objetivo desse subprojeto foi mensurar as condições climáticas do espaço aberto nos valores de temperatura, umidade e vento, verificando o papel das áreas verdes no microclima da cidade de Juazeiro, visto ser uma cidade tipicamente semiárida. 
O estudo foi possível com o uso da estação meteorológica móvel ${ }^{5}$, durante três dias, em ambiente seco (asfaltado) e ambiente verde (arborizado), cuja finalidade foi comparar o conforto ambiental de espaços abertos entre áreas com características estruturais e morfológicas diferentes. As estações foram posicionadas em dois (02) pontos nas proximidades do DCHIII/UNEB, com condições diferentes de materiais e vegetação.

Os resultados apontaram que em relação à temperatura, a diferença dos ambientes verdes para os secos é de $-2,49^{\circ} \mathrm{C}$ e, em relação à umidade, $4 \%$ mais úmidos.

Muitas são as funções, vantagens e importância do verde para a cidade para a manutenção da qualidade do ar urbano, dentro de padrões adequados às necessidades dos indivíduos humanos e do meio ambiente, pois as áreas verdes possuem papel relevante na sustentabilidade do equilíbrio ecológico do biótopo e da biocenose do ecossistema urbano, afirma Carvalho (1999).

- Memória e Cidade:

Este subprojeto parte do pressuposto que os espaços urbanos têm personalidade, pois são representações simbólicas que se constituem como coloca Bosi (2003, p.200), “[...] em lugares privilegiados de onde a memória retira sua seiva".

As questões problematizadas foram: Qual a relação entre o verde e a cidade na memória dos seus habitantes (individual e coletiva)? Qual o papel do verde urbano na bricolagem do tempo, nas relações sociais projetadas no espaço, que organizam a vida e que revelam o conteúdo existencial do espaço vivido?

No momento em que a sociedade contemporânea procura alternativas para viver com qualidade nas cidades, insatisfeita com a forma de pensamento hegemônico que desumaniza as relações sociais e mercantiliza a vida, que coisifica a natureza como um recurso a ser explorado, compreender a presença do verde nos lugares da memória urbana significa percebê-lo como elemento de ressignificação das relações entre as pessoas e sua cidade através da própria natureza Semiárida.

O subprojeto usou como recurso, fotografias antigas da cidade para revelar testemunhos da paisagem urbana pretérita e as transformações ocorridas ao longo do tempo. Outro instrumento utilizado foi à entrevista semiestruturada, aplicada a cinquenta e sete (57) transeuntes. A escolha desses sujeitos foi aleatória e, após mostrar ao entrevistado uma foto histórica do local da entrevista, o entrevistador preencheu um questionário com 9 perguntas.

\footnotetext{
${ }^{5}$ Equipamento adquirido com recursos do edital 008/2012 FAPESB. 
Outros procedimentos utilizados nesse subprojeto foi o uso da memória fotográfica prospectada na Biblioteca e Museu Municipais e no acervo disponível na WEB.

A intenção foi compreender como esses sujeitos têm estabelecido suas relações com espaço urbano e, nele, especialmente com o verde. Desta forma, a questão central desse subprojeto é compreender como os citadinos juazeirenses têm percebido a presença/ausência do verde na organização espacial da sua cidade. Para tanto, tem investigado a partir da memória desses sujeitos, as suas narrativas e vivências entrecruzadas no uso dos espaços públicos, tais como, as praças, as ruas, a ponte, a orla, enfim espaços vividos em presença do verde.

\section{- Conviverde nas Escolas:}

Este Subprojeto está fundamentado nas diretrizes da Educação Contextualizada para a Convivência com o Semiárido, considerando que estas se baseiam nas dimensões complexa e decolonial para gerar conhecimento contextualizado sobre a natureza, a sociedade e o território Semiárido, focando a vida, a produção e a cultura nesse contexto.

A metodologia usada foi por meio da realização de Oficinas de desenhos/Mapas mentais com crianças/pré-adolescentes de 6 a 13 anos de idade, do $2^{\circ}$ ao $5^{\circ}$ anos do Ensino Fundamental de cinco escolas públicas municipais de Juazeiro, de 2013 a 2016. Também ofertou por meio desse Subprojeto, três cursos de extensão (ECSAB, Verde Urbano; Mobilidade Susentável), Encontros com docentes e gestores e Assessoria Pedagógica em ECSAB, além da oferta de um kit de obras especializadas em Educação Contextualizada para o acervo das escolas-parceiras e do DVD "Por um Olhar Verde nas Escolas"6 para os professores usarem em suas aulas.

A $1^{\text {a }}$ Oficina foi denominada de "A Juazeiro que percebo". Nessa oficina objetivou identificar as representações sócio espaciais que os alunos têm sobre sua cidade e quais elementos da natureza e da cultura semiárida percebiam e se apropriavam como contexto de sua territorialidade. Deste modo, foi usada a técnica do Mapa Mental (Trajeto casa-escola) para permitir que as crianças expressassem o que veem e compreendem do mundo e da sociedade que as envolvem ou e as excluem enquanto sujeitos de direito à cidade na qual vivem. Segundo Leite (1998, p.140), “a criança pinta e desenha o que sente ou sabe que existe, mesmo que não seja o que é possível ver”.

Como resultado dessa Oficina, foi identificado a forte presença do rio São Francisco, da ponte Presidente Dutra (ligação entre Juazeiro -BA e Petrolina-PE), das estátuas

\footnotetext{
${ }^{6}$ Produzido pela TV Caatinga/UNIVASF em parceria com o NEPEC-SAB, em 2015. 
localizadas no Rio São Francisco (o Nego d'Água e a Sereia), da orla fluvial de Juazeiro com seus barcos e do Vaporzinho Alm. Saldanha, além de algumas Carrancas. Tais pontos da cidade se colocaram não diretamente como referências espaciais do espaço vivido, mas imagens espaciais elaboradas a partir do conhecem a cidade por meio da televisão.

A vegetação representada apontou a espécie Juazeiro, considerado por muitas crianças o símbolo da cidade. No entanto, o verde urbano desenhado marca a forte presença das árvores exóticas que dominam a paisagem, como exemplo, o Ficus ou de algumas não existentes na paisagem, mas na memória visual, tais como, o morango e a maça.

$\mathrm{Na} 2^{\text {a }}$ Oficina denominada de "Juazeiro, te quero verde", foi mantida a técnica do Mapa Mental, mas desta vez, desenhando o que seria em seu imaginário, sua cidade sustentável. A intenção aqui foi identificar quais noções de sustentabilidade às crianças têm produzido e concebem Juazeiro como um lugar bom para se viver, mediante seu imaginário de "cidade sustentável".

Nessa $2^{\text {a }}$ Oficina, foi observado que as crianças não tinham um amplo conhecimento espacial da cidade, e se prenderam mais no desenho do seu bairro e/ou escola. Como referência predominante do contexto urbano, foi a Ponte Presidente Dutra.

Os desenhos produzidos nas $1^{\mathrm{a}}$ e $2^{\mathrm{a}}$ Oficinas foram interpretados com base nos fundamentos da Geografia Cultural-Humanista, da Educação Contextualizada e na Arteterapia trabalhada por Rabello (2014), que possibilitaram apreender tanto a cidade percebida quanto a cidade imaginada a partir de traços, curvas, cores, texturas e dimensões dadas nos desenhos infantis, que nos revelaram Juazeiro, uma cidade Semiárida cheia de contradições, mas de muitas possibilidades.

\section{NOTAS FINAIS}

O Projeto de pesquisa CONVIVERDE, ao longo dos quatro anos de atuação (201216) vem assumindo a grande tarefa de criar e consolidar uma Rede Ambiental para pensar, coletivamente, a construção, implementação e gestão de um sistema verde urbano e de mobilidade sustentável na cidade de Juazeiro, Bahia. Para tal investidura, elegeu-se caminhar com ações participativas e educativas contextualizadas e de convivência com o Semiárido Brasileiro.

O CONVIVERDE ao atuar com as três áreas do conhecimento, Geografia, Arquitetura e Educação, busca de forma interdisciplinar, investigar a situação socioambiental 
dessa importante cidade semiárida. Tal desafio só é possível a partir da metodologia de investigação calcada no conhecimento contextualizado e complexo das especificidades do contexto geoambiental do Semiárido Brasileiro. Esta perspectiva se inova por tratar das condições urbanas semiáridas, que ainda são pouco presentes nas reflexões e debates acerca desse território, no sentido de contribuir para ampliar o conhecimento sobre suas territorialidades urbanas.

Com os resultados alcançados até então, já é possível problematizar o que limita e possibilita as cidades do Semiárido serem cidades sustentáveis, dentro da perspectiva do novo paradigma de "cidades inteligentes", como afirma Mark Roseland (1987), "A cidade sustentável requer a criação de uma nova lógica de funcionamento, gestão e crescimento".

O projeto realiza pesquisas no contexto urbano de Juazeiro (Bahia), mas são temáticas diretamente ligadas à urbanização, à sustentabilidade, às territorialidadades dos sujeitos, e que mesmo contextualizadas no Semiárido Brasileiro, não deixam de ser questões amplas, que dizem respeito às relações da sociedade contemporânea com o meio urbano. Enfim, são questões que necessitam ser problematizadas seja para qualquer cidade e refletidas de forma crítica e propositiva pelos cidadãos e gestores para que juntos, se encontre formas mais prudentes e sustentáveis de se conviver com a cidade.

\section{REFERÊNCIAS}

ABRAMOVAY, Ricardo. O Futuro das Regiões Rurais. Porto Alegre: Editora da UFRGS, 2003.

BONNEMAISON, Joel. Viagem em torno do território. In: CORREA R. ROSENDHAL, Z. (Org.). Geografia Cultural. Rio de Janeiro: EdUERJ, 2002

BOSI, Ecléa. Memória da Cidade: Lembranças Paulistanas. In: Caderno Estudos Avançados, n.47, v.17. Instituto de Estudos Avançados da USP. São Paulo: jan./abr. 2003. Disponível em: http://www.scielo.br/scielo.php. Acesso em: 06/09/2017.

BRASIL. Ministério do Meio Ambiente. Secretaria de Recursos Hídricos; Universidade Federal da Paraíba. Atlas das Áreas Susceptíveis à Desertificação do Brasil. Brasília (DF), 2007.

BRASIL. Ministério do Meio Ambiente.Secretaria de Recursos Hídricos.Coordenação Técnica de Combate à Desertificação. Plano de Ação Nacional de Combate à 
Desertificação e Mitigação dos efeitos da Seca. Relatório III Oficina Nacional. Olinda (PE), 2004

CARVALHO, Maria Lúcia A.M. O espaço do verde na Área Metropolitana de Salvador. 1999.Tese (Doutorado em Geografia) - UNESP, Rio Claro, São Paulo.

CARVAlHO, Luzineide Dourado. Natureza, Território e Convivência: Novas Territorialidades no Semiárido Brasileiro. Jundiaí: Paco Editorial, 2012.

HOLZER, Werten. O Conceito de Lugar na Geografia Cultural-Humanista: Uma Contribuição para a Geografia Contemporânea. In: Revista da Pós-Graduação em Geografia. Departamento de Geografia, UFF, Rio de Janeiro, Ano V, n. 10, 2003.

LEITE, Maria Isabel Ferraz Pereira. Desenho Infantil: In: KRAMER S.e LEITE, M. I.F. P. (Orgs.). Infância e Produção Cultural. São Paulo: Papirus, 1998 (Serie Prática Pedagógica).

RABELLO, Nancy. O Desenho infantil: Entenda como a Criança se Comunica por meio de Traços e Cores, Rio de Janeiro: Wak Editora, 2014.

ROSELAND, Mark. Cidades Sustentáveis: Uma Nova Conjuntura Urbana. Disponível em: http://www.casadaclea.wordpress.com. Acesso em: 06/09/2017

SCHAFER A. The Global Demand for Motorized Mobility. Transportation Research A, 32,1998

TUAN, Yi-Fu. Geografia Humanística. In: CHRISTOFOLETTI, A. (Org.). Perspectivas da Geografia. São Paulo: DIFEL, 1985. p. 143-164. 